\title{
Impact of insecticide treated mosquito nets and low dose monthly diethylcarbamazine on lymphatic filariasis infection between 1999 and 2004 in two endemic communities of north-eastern Tanzania
}

\author{
MARTHA M. LEMNGE ${ }^{*}$, BRUNO P. MMBANDO ${ }^{1}$, METHOD D. SEGEJA ${ }^{1}$, SAMWEL GESASE ${ }^{1}$ and \\ IB C. BYGBJERG ${ }^{2}$ \\ ${ }^{1}$ National Institute for Medical Research, Tanga Medical Research Centre, Tanzania \\ ${ }^{2}$ Centre for Medical Parasitology at the Institute of International Health, Immunology and Microbiology, \\ Faculty of Health Sciences, University of Copenhagen, Denmark
}

\begin{abstract}
Lymphatic filariasis (LF) is among the poverty related neglected tropical diseases earmarked for elimination using mass drug administration (MDA) strategy. Additional use of insecticide treated mosquito nets (ITNs) might enhance elimination of LF infection. Between August 1998 and July 1999, all individuals aged $\geq 8$ months from Magoda and Mpapayu villages in northeastern Tanzania, were administered with monthly low dose diethylcarbamazine (DEC) at a dosage of $50 \mathrm{mg}$ in children aged $<15$ years and $100 \mathrm{mg}$ in adults aged $\geq 15$ years. ITNs were also distributed to Magoda in December 1998 and to Mpapayu in March 2001. The main objective of our study was to assess the impact of ITNs and low dose DEC on microfilaria ( $m f$ ) prevalence and intensity and incidence of new $m f$ infections. Four annual cross-sectional surveys were conducted between 1999 and 2004 in the two villages to screen for Wuchereria bancrofti microfilariae in individuals aged $\geq 1$ year. Overall, $80 \%$ of the population in Magoda and $66 \%$ in Mpapayu were covered during these surveys. Results revealed a significant decrease in both $m f$ prevalence and intensity in both villages. Furthermore, there was a steady decrease in $m f$ incidence in Magoda; with 36.7 cases per 1000 person years in 2000 and 7.4 in 2004. In Mpapayu, the incidence initially increased from 20.8 cases in 2000 to 24.3 in 2001 and then decreased to 7.2 cases in 2004. Individuals using ITNs in Magoda had significantly lower risk of $m f(\mathrm{OR}=0.681 ; 95 \% \mathrm{CI}$ : $0.496-0.934)$; and the risk of new infections was reduced by $58.8 \%$ (95\% CI: 30.3-75.4). These results suggest that when MDA is complemented with ITNs there is high likelihood to half filariasis transmission within a shorter period than using chemotherapy alone.
\end{abstract}

Keywords: Diethylcarbamazine, lymphatic filariasis, insecticide mosquito nets, Tanzania

\section{Introduction}

Lymphatic filariasis (LF) resulting from infection with the mosquito borne filarial nematode Wuchereria bancrofti, is one of the major public health problems affecting millions of people in tropical countries (Michael \& Bundy 1997; Simonsen et al., 2002). World Health Organization has earmarked LF for elimination using mass drug administration. Previous studies in Tanzania have shown that monthly low-dose treatment with DEC for one year produced marked effect on microfilariae $(m f)$ intensities (Meyrowitsch et al., 1996; Meyrowitsch \& Simonsen 1998). Another study in Tanzania (Meyrowitsch et al., 2004) observed a static pattern of infection and disease in individuals followed up for 26 years after initial interventions. They found that those infected in the past had a higher chance of acquiring a new detectable infection.

Vector control is another means of control of LF, where results from other studies have indicated benefit of using mosquito nets in control of infection (Bockarie et al., 2002a; Bockarie et al., 2009; Bogh et al., 1998; Michael et al., 2004; Odermatt et al., 2008; Pedersen \&

* Correspondence: Martha Moshi Lemnge; E-mail: marthalemnge@yahoo.com or mlemnge@nimr.or.tz 
Mukoko, 2002). Bockarie et al. (2002a) reported lower W. bancrofti $m f$ prevalence, antigenaemia and hydrocoele prevalence among mosquito net users compared to non-users in Papua New Guinea. Their findings suggest that untreated mosquito nets can protect against $W$. bancrofti infection. Modelling of data from low, moderate and high transmission communities from East Africa (Michael et al., 2001) found that in areas of higher parasite transmission, community $m f$ prevalence may increase with transmission intensity until herd immunity controls it. Another study (Michael et al., 2004) indicated that successful filariasis control would need high coverage of community treatment and inclusion of vector control measures; particularly in areas of high endemicity. The importance of adding vector control to LF elimination programmes has been well summarized in a recent article by Bockarie et al. (2009) where the authors, using mathematical modelling, propose three major strategic roles of vector control. They urge that including vector control to LF elimination programmes would reduce number of years of required drug administration, lower drug coverage requirement, and sustain long-term parasite elimination from treated communities.

Filariasis survey conducted in Magoda in north-eastern Tanzania in 1992 found overall W. bancrofti mf prevalence of $29 \%$ (Simonsen et al., 1996). In 1997, another survey involving both Magoda and Mpapayu villages revealed around 28.5\% $\mathrm{mf}$ prevalence (Bernhard et al., 2000). These two villages provided an opportunity to assess the added advantage of adding insecticide treated mosquito nets (ITNs) to a low dose DEC treatment for LF that had been offered earlier on (P. Bernhard, unpublished data). The aims of this study were, therefore, to: assess the impact of ITNs and low dose DEC on prevalence and intensity of microfilaraemia, incidence of $m f$ infections and prevalence of LF chronic infections. The study also aimed to determine the prevalence of circulating filarial antigens in children from the two villages. The data was envisaged to be useful for future monitoring of MDA program in the area. The findings of this longitudinal study might provide more data to model effect of ITNs in addition to mass drug administration in the control of filariasis.

\section{Materials and Methods}

\section{Study area and population}

The study was conducted in three villages named Magoda, Mpapayu and Mgome in Muheza district, north-eastern Tanzania. Magoda and Mpapayu villages are located at $5^{\circ} 11^{\prime} \mathrm{S}$ and $38^{\circ} 52^{\prime} \mathrm{E}$, and they are situated at a distance of $1 \mathrm{~km}$ apart. Details of the two villages are given elsewhere (Simonsen et al., 1996). ITNs were distributed free of charge in December 1998 in Magoda village and March 2001 in Mpapayu (Alifrangis et al., 2003). The ITNs were re-impregnated twice annually using Permethrin, with the assistance of village helpers and project staff. Between August 1998 and July 1999, all individuals aged $\geq 8$ months from Magoda and Mpapayu villages were given monthly DEC at a dosage of 50mg in children aged $<15$ years and $100 \mathrm{mg}$ in adults aged $\geq 15$ years (Meyrowitsch et al., 1996). Mgome village is situated $2 \mathrm{~km}$ away from Mpapayu and had low mosquito net coverage as described elsewhere (Lusingu et al., 2004). This village was not involved in the low dose DEC study. In all surveys, village population census surveys were conducted and census was updated a few months prior to the filariasis survey, where every individual was identified by unique identification number. The last population census survey in May 2004 also involved Mgome village. 
Entomological studies in Magoda (Mboera et al., 1997) showed that main vectors were Anopheles gambiae s.l. and An. funestus. However, no entomology was done in subsequent surveys described in the current study.

\section{Study design}

This was an observational study, where a series of four cross-sectional surveys were conducted to assess the impact of ITNs and low dose DEC on prevalence and intensity of microfilaraemia, incidence of $m f$ infections and chronic manifestations. The filariasis surveys were conducted in Magoda and Mpapayu once annually between July and September in 1999, 2000, 2001, and 2004. Schematic activities flow chart is as detailed in Figure 1.

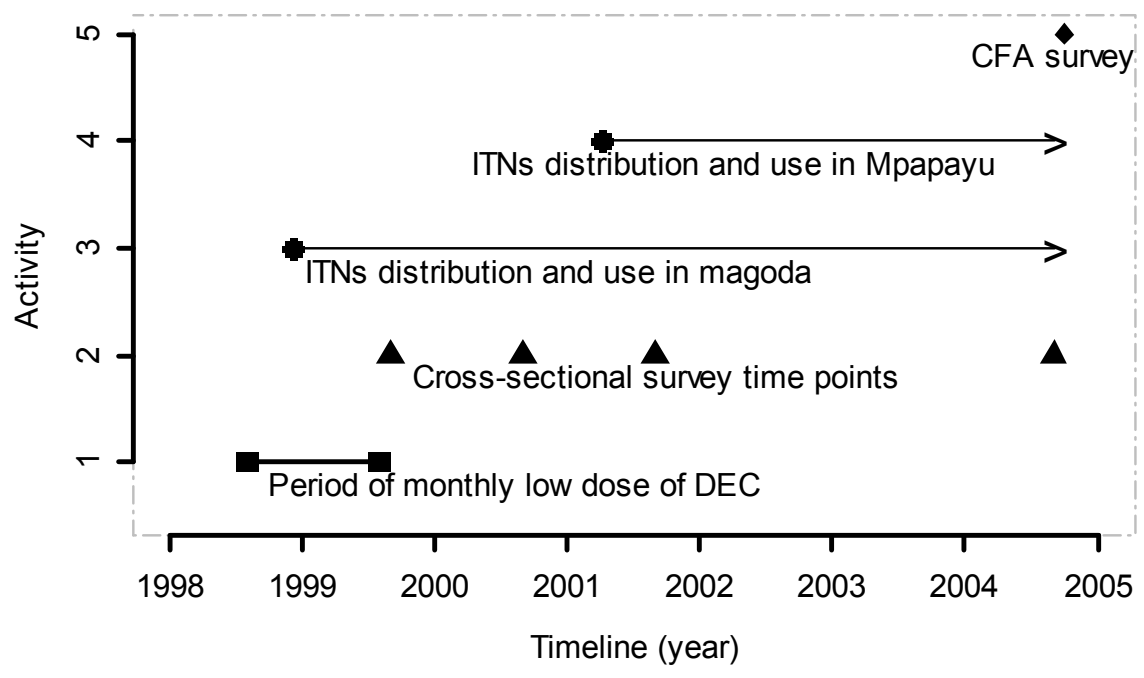

Figure 1: Timelines for different research activities

\section{Clinical and parasitological examination}

A morbidity questionnaire was used to collect information from each individual who consented to participate in the study. Physical examination was carried out during the day and focused on chronic clinical manifestations of lymphatic filariasis which were identified and recorded accordingly (Meyrowitsch et al., 1995b).

Blood collection for $m f$ was carried out between 21.00 and $1.00 \mathrm{~h}$. A $100 \mu \mathrm{l}$ of finger prick blood was collected in heparinised capillary tube and the specimen was immediately transferred into $1 \mathrm{ml}$ plastic eppendorf tube with $900 \mu \mathrm{l}$ of $3 \%$ acetic acid to make up $1000 \mu \mathrm{l}$. At the laboratory, specimen was quantified using counting chamber technique according to McMahon et al. (1979) and the number of $m f$ per $\mathrm{ml}$ was calculated.

In September 2004, a cross-sectional survey involving children aged 1 to 9 years was conducted to screen for circulating filarial antigen (CFA). An ICT test (Now ICT, Binax Inc., Maine, U.S.A) which is more sensitive and specific for the detection of CFA in children was used. Whole blood specimen of $50 \mu \mathrm{l}$ volume was collected using a capillary tube and applied to the ICT card according to instructions from the manufacturer. The results were read after 10 minutes. A test was declared negative only if a single line was observed on the strip and positive if two lines were observed. 


\section{Ethical consideration}

The study was approved by both the Medical Research Coordinating Committee of the National Institute for Medical Research and Tanzania Commission for Science and Technology. The study was also reviewed and recommended by the Central ScientificEthical Committee of Denmark. The study adhered to the principles of Helsinki II Declaration. Furthermore, meetings were held in the study communities to explain the purpose of the study and the procedures involved. All villagers in the study communities were asked to give their verbal consent in Kiswahili to participate in the study and confidentiality of the given information was assured to all. Children were enrolled into the study after their parents or guardians had given informed consent. Study participants presenting with minor illnesses during fieldwork received free medical treatment from the study team or the mobile clinic. Individuals presenting with severe illnesses were referred to the district hospital in Muheza. Mass drug administration using albendazole and ivermectin was introduced in these and other villages in Muheza in October 2004, following introduction of LF elimination by the National Lymphatic Filariasis Elimination Programme.

\section{Statistical analysis}

Data management was done using Epi6.04d and analysis was done using STATA (version 8.0) and $\mathrm{R}$ statistical software. $M f$ count was adjusted for the sampling time as described elsewhere (Simonsen et al., 1997). The impact of the interventions on lymphatic filariasis infection and chronic manifestations was assessed by comparing values obtained from the consecutive surveys to those at baseline. Chi-square test was used to compare proportions. Geometric mean intensity (GMI) of $m f$ was calculated for: (1) all examined individuals and (2) for individuals who were positive for $m f$. More than $70 \%$ of individuals examined during the four rounds participated in more than one survey; so observations within individuals were correlated. Hence, generalized estimating equation (GEE) model was used in the analyses.

Models adjusted for covariates in both binary (microfilariae status positive/negative) and continuous (microfilariae counts) response variables were fitted to determine association between $m f$ infection and time as well as the effect of ITNs at population level. The GEE was also used to model the chronic filariasis pathology (elephantiasis and hydrocoele). Incidence of $m f$ was defined as number of new cases of $m f$ detected during the follow-up time, where follow-up time started at any survey round where a person was examined for the first time (entry point). Any individual found positive for $m f$ infection at the entry point was censored, while the rest were followed-up to monitor whether they became $m f$ positive. An $m f$ episode was defined as new if a person was $m f$ negative in the previous survey(s). The first survey July-August 1999 was considered as the baseline. A Pvalue $<0.05$ was considered significant.

\section{Results}

\section{Mf prevalence and density}

Overall, $80 \%$ and $66 \%$ of population in Magoda and Mpapayu respectively, were covered during cross-sectional surveys. There was a significant decreasing trend of $m f$ prevalence across the years in both villages; from $14 \%$ in 1999 to $5.1 \%$ in 2004 in Magoda $\left(\chi^{2}\right.$ trend $=43.7$, $\mathrm{p}<0.001)$ and from $11.8 \%$ to 5.9 in Mpapayu village $\left(\chi^{2}\right.$ trend $\left.=9.25, \mathrm{p}=0.002\right)$, (Table 1$)$. 
Table 1: Number of individuals examined, ITN coverage, $m f$ intensity and prevalence of $m f$ and chronic manifestations by village survey date. Denominator in proportions is the number of individuals examined

\begin{tabular}{|c|c|c|c|c|c|c|}
\hline Survey date & $\begin{array}{l}\text { No. } \\
\text { examined } \\
\text { (males) }\end{array}$ & $\begin{array}{l}\text { No. using } \\
\text { ITNs (\%) }\end{array}$ & $\begin{array}{l}M f \\
\text { prevalence } \\
m f(95 \% \mathrm{CI})\end{array}$ & $\begin{array}{l}\text { GMIs } \\
(95 \% \mathrm{CI})\end{array}$ & $\begin{array}{l}\text { Hydrocoele } \\
\text { prevalence * } \\
(95 \% \mathrm{CI})\end{array}$ & $\begin{array}{l}\text { Lymphoedema } \\
\text { prevalence } \\
(95 \% \mathrm{CI})\end{array}$ \\
\hline \multicolumn{7}{|l|}{ Magoda } \\
\hline $\begin{array}{l}\text { July-Aug } \\
1999\end{array}$ & $\begin{array}{l}1059 \\
(488)\end{array}$ & $\begin{array}{l}958 \\
(90.72)\end{array}$ & $\begin{array}{l}13.96 \\
(11.94-16.21)\end{array}$ & $\begin{array}{l}1.99 \\
(1.78-2.22)\end{array}$ & $\begin{array}{l}12.50 \\
(9.70-15.77)\end{array}$ & $\begin{array}{l}2.55 \\
(1.69-3.69)\end{array}$ \\
\hline $\begin{array}{l}\text { July-Aug } \\
2000\end{array}$ & $\begin{array}{l}1002 \\
(464) \\
\end{array}$ & $\begin{array}{l}879 \\
(87.72) \\
\end{array}$ & $\begin{array}{l}8.78 \\
(7.1-10.71) \\
\end{array}$ & $\begin{array}{l}1.59 \\
(1.44-1.75)\end{array}$ & $\begin{array}{l}10.99 \\
(8.29-14.20) \\
\end{array}$ & $\begin{array}{l}2.40 \\
(1.54-3.54)\end{array}$ \\
\hline $\begin{array}{l}\text { Aug-Sept } \\
2001\end{array}$ & $\begin{array}{l}1017 \\
(431)\end{array}$ & $\begin{array}{l}967 \\
(97.67) \\
\end{array}$ & $\begin{array}{l}5.60 \\
(4.72-7.20) \\
\end{array}$ & $\begin{array}{l}1.34 \\
(1.27-1.50) \\
\end{array}$ & $\begin{array}{l}14.38 \\
(11.21-18.07) \\
\end{array}$ & $\begin{array}{l}1.67 \\
(0.98-2.66) \\
\end{array}$ \\
\hline $\begin{array}{l}\text { Aug-Sept } \\
2004\end{array}$ & $\begin{array}{l}1070 \\
(479) \\
\end{array}$ & $\begin{array}{l}976 \\
(92.60) \\
\end{array}$ & $\begin{array}{l}5.14 \\
(3.90-6.64) \\
\end{array}$ & $\begin{array}{l}1.40 \\
(1.28-1.53) \\
\end{array}$ & $\begin{array}{l}16.08 \\
(12.90-19.68) \\
\end{array}$ & $\begin{array}{l}2.06 \\
(1.29-3.10) \\
\end{array}$ \\
\hline $\begin{array}{l}\text { Test for } \\
\text { trend }\end{array}$ & & & $\begin{array}{l}\chi^{2} \text { trend }=43.7 \\
p<0.001\end{array}$ & $\begin{array}{l}z=-6.51 \\
p<0.001\end{array}$ & $\begin{array}{l}\chi^{2} \text { trend }=4.35 \\
p=0.037\end{array}$ & $\begin{array}{l}\chi^{2} \text { trend }=0.49 \\
p=0.482\end{array}$ \\
\hline \multicolumn{7}{|l|}{ Mpapayu } \\
\hline Aug1999 & $\begin{array}{l}757 \\
(340)\end{array}$ & $\begin{array}{l}12 \\
(1.59) \\
\end{array}$ & $\begin{array}{l}11.76 \\
(9.55-14.27)\end{array}$ & $\begin{array}{l}1.81 \\
(1.60-2.05)\end{array}$ & $\begin{array}{l}21.18 \\
(16.95-25.91) \\
\end{array}$ & $\begin{array}{l}2.51 \\
(1.52-3.89)\end{array}$ \\
\hline Aug 2000 & $\begin{array}{l}682 \\
(288)\end{array}$ & $\begin{array}{l}9 \\
(1.33)\end{array}$ & $\begin{array}{l}5.12 \\
(3.59-7.06) \\
\end{array}$ & $\begin{array}{l}1.33 \\
(1.21-1.46) \\
\end{array}$ & $\begin{array}{l}19.08 \\
(14.67-24.15) \\
\end{array}$ & $\begin{array}{l}1.47 \\
(0.71-2.68) \\
\end{array}$ \\
\hline Sept 2001 & $\begin{array}{l}693 \\
(312) \\
\end{array}$ & $\begin{array}{l}683 \\
(99.71) \\
\end{array}$ & $\begin{array}{l}7.65 \\
(5.79-9.90) \\
\end{array}$ & $\begin{array}{l}1.56 \\
(1.39-1.76) \\
\end{array}$ & $\begin{array}{l}20.72 \\
(16.31-25.72) \\
\end{array}$ & $\begin{array}{l}1.30 \\
(0.60-2.46) \\
\end{array}$ \\
\hline Sept 2004 & $\begin{array}{l}723 \\
(320) \\
\end{array}$ & $\begin{array}{l}642 \\
(89.29) \\
\end{array}$ & $\begin{array}{l}5.95 \\
(4.34-7.93) \\
\end{array}$ & $\begin{array}{l}1.49 \\
(1.33-1.68) \\
\end{array}$ & $\begin{array}{l}20.75 \\
(16.43-.25 .63) \\
\end{array}$ & $\begin{array}{l}1.80 \\
(0.96-3.06) \\
\end{array}$ \\
\hline $\begin{array}{ll}\text { Test for } \\
\text { trend }\end{array}$ & & & $\begin{array}{l}\chi^{2} \text { trend }=9.25 \\
p=0.002\end{array}$ & $\begin{array}{l}z=-2.77 \\
p=0.01\end{array}$ & $\begin{array}{l}\chi^{2} \text { trend }=0.00 \\
p=0.946\end{array}$ & $\begin{array}{l}\chi^{2} \text { trend }=0.41 \\
p=0.523\end{array}$ \\
\hline
\end{tabular}

* For males only; §Geometric mean intensity (GMI) calculated based on all individuals; $\mathrm{CI}=$ confidence interval

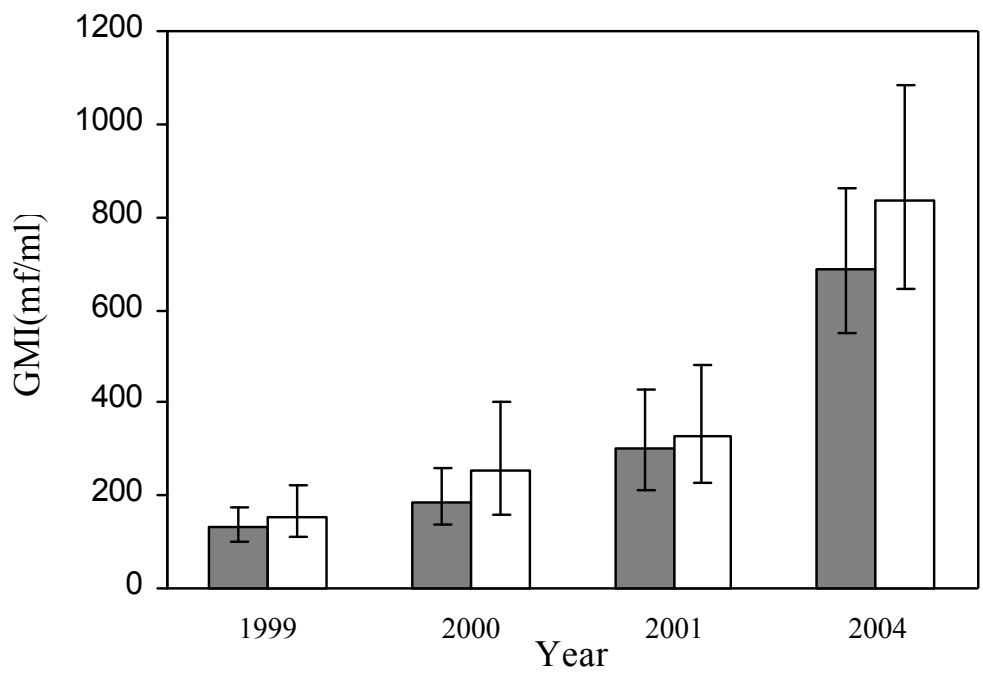

Figure 2: Geometric mean intensity of Wuchereria bancrofti $m f$ among individuals examined and found positive during 1999-2004 surveys in Magoda (filled bars) and Mpapayu (open bars)

A steady decrease in prevalence was seen in Magoda throughout, while in Mpapayu, a similar trend was seen except in 2001, where there was a slight increase in prevalence. When 
geometric mean intensity (GMI) calculated based on all examined individuals was considered, there was a significant decrease in the intensity across the years in both, Magoda $(\mathrm{p}<0.001)$ and Mpapayu villages $(\mathrm{p}=0.01)$ (Table 1$)$. However, when taking an account of $m f$ positive individuals only, the GMI increased across the years, and the mean intensity in Mpapayu was higher than that of Magoda village (Figure 2).

Adjusted analysis showed that the risk of $m f$ infection was significantly lower by $46 \%$ $(\mathrm{p}=0.002)$ in residents of Mpapayu compared to Magoda (Table 2). Furthermore, interaction between village and year showed that the risk of $m f$ in Mpapayu village was more than 2 folds in 2001 and 2004 compared to Magoda in the same periods. These results showed that despite Mpapayu having lower prevalence at the beginning, the rate of decrease in prevalence of $m f$ infection was slower in Mpapayu than in Magoda village. Variables that were associated with reduced risk of being $m f$ positive were age, use of ITNs and gender (females) (Table 2). The risk of $m f$ infection was very low (one third) in individuals using ITNs compared to those not using any mosquito net.

Table 2: Estimates of parameters from univariate and multivariate analyses of risk factors associated with Wuchereria bancrofti microfilariae infection in Magoda and Mpapayu

\begin{tabular}{lccccr}
\hline & \multicolumn{2}{c}{ Univariate analysis } & \multicolumn{3}{c}{ Multivariate analysis } \\
Variable & OR & p-value & OR & $95 \%$ CI & P-value \\
\hline Village-Mpapayu & 0.920 & 0.335 & 0.536 & $0.362-0.793$ & 0.002 \\
\hline Year 1999 & 1 & & 1 & & \\
$\quad 2000$ & 0.528 & $<0.001$ & 0.543 & $0.454-0.648$ & $<0.001$ \\
$\quad 2001$ & 0.456 & $<0.001$ & 0.355 & $0.279-0.451$ & $<0.001$ \\
$\quad 0.388$ & $<0.001$ & 0.307 & $0.236-0.400$ & $<0.001$ \\
\hline Mpapayu-year 2000 & & & 0.776 & $0.553-1.087$ & 0.140 \\
Mpapayu-year 2001 & & & 2.346 & $1.490-3.692$ & $<0.001$ \\
Mpapayu-year 2004 & & & 2.265 & $1.432-3.583$ & $<0.001$ \\
\hline Age & & & 1.130 & $1.108-1.153$ & $<0.001$ \\
Age square & & & 0.999 & $0.998-0.999$ & $<0.001$ \\
Sex (female) & 0.548 & $<0.001$ & 0.499 & $0.391-0.637$ & $<0.001$ \\
\hline No mosquito net & 1 & & 1 & & \\
Net (ITN) & 0.721 & $<0.001$ & 0.681 & $0.496-0.934$ & 0.017 \\
Net (Not ITN) & 0.657 & 0.101 & 1.132 & $0.766-1.674$ & 0.534 \\
\hline
\end{tabular}

\section{New mf infection}

A total of 1925 individuals (1137 from Magoda and 788 from Mpapayu villages) were included in this analysis. The total follow-up time was 9427 person years, whereby in Magoda the follow-up time was 5529 and Mpapayu was 3898 person years. A total of 127 individuals (77 from Magoda and 50 from Mpapayu) were infected during the follow-up time giving incidence rate of 13.93 (95\%CI: 11.14-17.41) and 12.83 (95\%CI: 9.72-16.92) per 1000 person years for Magoda and Mpapayu, respectively. There was a steady decrease in the rate of infection in Magoda whereby in 2000 the incidence was 36.7 (95\%CI: 26.1-51.7) while in 2004 it was 7.4 (95\%CI: 5.1-10.9) cases per 1000 person years. In Mpapayu, the incidence initially increased from 20.8 (95\%CI: 12.08-35.82) cases in 2000 to 24.3 (95\%CI: 15.638.2) cases in 2001 but then decreased to 7.2 cases per 1000 person years in 2004 (Figure 3). 


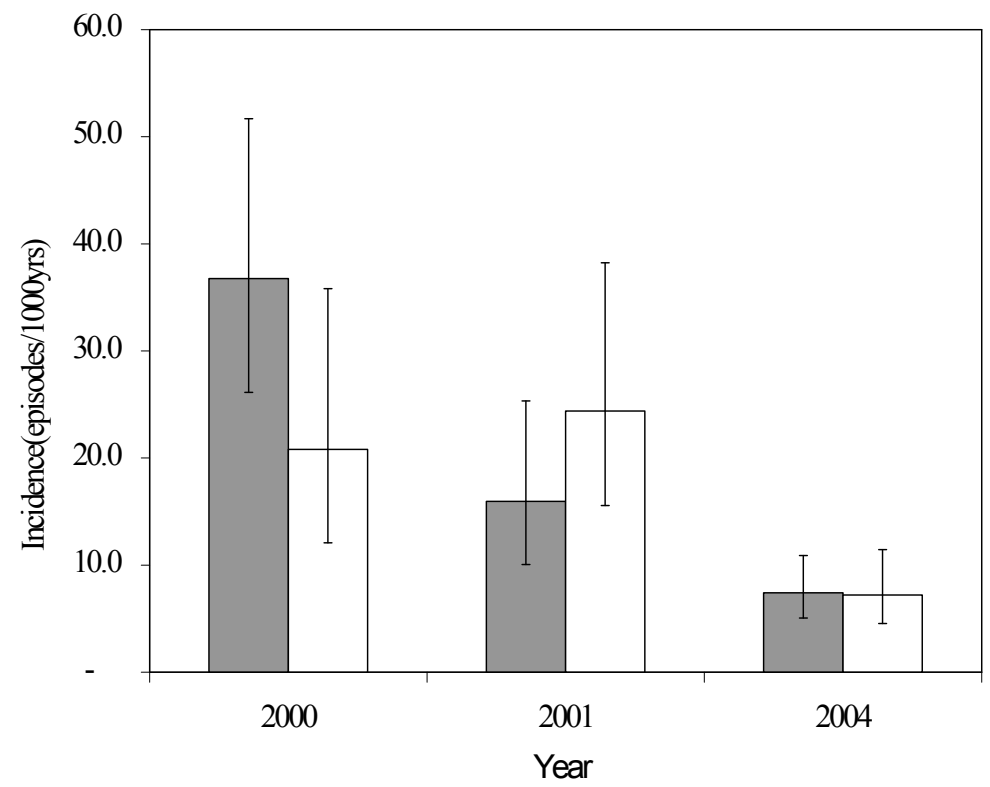

Figure 3: Incidence of Wuchereria bancrofti $m f$ infection per 1000 person years (with $95 \% \mathrm{CI}$ ) in Magoda (filled bars) and Mpapayu (open bars), 2000-2004

Logistic regression showed that risk factors for new infections were age (OR=1.13, 95\%CI: 1.09-1.17, $\mathrm{p}<0.001)$, sex being male ( $\mathrm{OR}=2.15 ; 95 \% \mathrm{CI}: 1.49-3.12, \mathrm{p}<0.001)$; while in individuals using ITNs the risk was reduced by $58.8 \%$ (95\%CI: 30.3-75.4, $\mathrm{p}=0.001)$.

\section{Circulating filarial antigen}

A total of 472 children aged 1-9 years were examined in the 2004 survey from Magoda and Mpapayu. Only $9(1.9 \%)$ of the children tested positive with ICT. Median age of children who tested positive with ICT was 7.5 years and the youngest child who was positive with ICT was aged 4.8 years old. Comparing the two villages, only 1\% (3/281) children from Magoda showed positive result with ICT while in Mpapayu 3.1\% (6/191) were positive, and the prevalence was similar between males and females. Microscopy results in the four surveys showed that the prevalence in the same age group (1-9 years) in Magoda was 1.9\% (6/313), $0.7 \%$ (2/300), 0.3\% (1/320) and 0.3\% (1/328) in 1999, 2000, 2001 and 2004, respectively. In Mpapayu, $m f$ prevalence was 2.0\% (4/201), $0 \%(0 / 179), 0.6 \%(1 / 171)$ and $1.0 \%(2 / 203)$ in 1999, 2000, 2001 and 2004, respectively.

In Magoda and Mpapayu, children who were $m f$ positive by microscopy in 2004 were also positive with ICT card except for 1 case from Magoda whose status was missing because the child did not appear during ICT screening. For Mgome village, 116 children were included and 8 (6.9\%) were positive. Comparing data from Magoda and Mpapayu which had low dose DEC and ITNs with Mgome which had neither DEC nor ITNs, it was found that the odds ratio of being CFA positive in Mgome was 3.8 times higher (95\%CI: 1.24 - 11.38, $\mathrm{p}=0.009$ ). The median age for infected children in Mgome was 8.4 years, and the youngest infected child was aged 5.2 years. 


\section{Chronic pathology}

The overall prevalence of hydrocoele was significantly higher in males from Mpapayu $(20.5 \%)$ compared to those from Magoda $(13.5 \%),\left[\chi^{2}=26.83, p<0.001\right]$. There was a significant increasing trend of hydrocoele prevalence across the years in Magoda village $\left(\chi^{2}\right.$ trend $=4.35$, $\mathrm{p}=0.037$ ) while in Mpapayu the trend was not significant ( $\mathrm{p}=0.946)$ (Table 1). Results from regression analysis showed that Mpapayu village had higher risk of hydrocoele than Magoda (OR=2.42; 95\%CI: 1.41-4.15, $\mathrm{p}=0.001)$, and that there was a slight decrease in prevalence in Mpapayu in 2000 followed by an increasing trend which was significant in 2004 (OR=1.68; 95\%CI: 1.17 - 2.42, p=0.005). Similarly, hydrocoele prevalence increased with age OR=1.12 (95\%CI: $1.20-1.27, \mathrm{p}<0.001)$. ITNs had no impact on hydrocoele prevalence $(p=0.421)$ or elephantiasis. Furthermore, there was no significant difference in prevalence of elephantiasis across years within the villages and, between the two villages $\left(\chi^{2}=1.143\right.$, $p=0.285$ ). No case of hydrocoele or elephantiasis was found in children below 10 years of age.

\section{Discussion}

This study was aimed at assessing added impact of insecticide treated mosquito nets when used together with diethylcarbamazine in the control of lymphatic filariasis. The study showed a decreasing trend in prevalence of $m f$ infection across the years in Magoda and Mpapayu villages. However, a greater impact was seen in Magoda village where ITNs were introduced first, following a one year use of low dose monthly diethylcarbamazine in both villages. The decrease in $m f$ prevalence was significant in 1999 in both villages, which could be explained mainly by the one year administration of low dose monthly DEC in both villages. Moreover, the steady decline in $m f$ prevalence in Magoda and slower rate of decrease in Mpapayu could be due to the early introduction of ITNs that helped prevent new infections (Odermatt et al., 2008). On the other hand, the initial decline in $m f$ prevalence in Mpapayu where ITNs were introduced later, could be that the effect of MDA was not sustained suggesting continuous MDA might be important, even when ITNs for vector control are available. In the absence of interventions, $m f$ infection can remain static for a long period as previously reported (Meyrowitsch et al., 1995a; 2004).

The higher prevalence of CFA seen in Mpapayu compared to Magoda might be due to late distribution of ITNs, hence, higher exposure to infective mosquito bites. This could also be the explanation for the higher CFA seen in a neighbouring village of Mgome which had received neither DEC nor ITNs. In our setting, these findings seem to further support the need for vector control in addition to MDA to maximize impact on transmission (Michael et al., 2004). An earlier study (Simonsen et al., 1996) found prevalence of circulating antigens positivity of around 28\% among children aged 1-4 years in Magoda village. This seems much higher compared to the current study, indicating reduced exposure; most likely due to the use of ITNs (Odermatt et al., 2008). The reduction of CFA to such levels is an indication of low transmission setting and that could be the result of MDAs together with other interventions within the area. On the other hand, it is also clear when population of adult worm is reduced then the levels of excretions (antigen) are also reduced, and this might have contributed to the observed CFA levels.

The reduction in $m f$ density seen among all examined individuals, despite treatment been stopped in 1999, might be due to some individuals clearing the adult worms which were producing new $m f$, and use of ITNs which might have prevented new infections. 
However, the increase in mean $m f$ intensity among positive cases could be explained by discontinuation of treatment. Lack of sustained reduction in $m f$ density, which was seen initially among positive cases in both villages, suggests long-term MDA is needed to bring down $m f$ density which is the reservoir of infection. This suggests that had the two interventions been administered at the same time it would have sustained the levels; but when provided separately or singly the effect could not be observed at the same point in time. It is important to note that DEC has macrofilaricidal activity, therefore it is likely that when killing a large number of adult worm population, young parasites $(\mathrm{mf})$ are also reduced hence low $m f$ density. This was also reported in previous studies in north-eastern Tanzania, where monthly low-dose treatment with DEC for one year produced marked reduction of $m f$ intensities (Meyrowitsch et al., 1996; Meyrowitsch \& Simonsen 1998).

The clear difference between the two villages in terms of prevalence of $m f$ infections indicates the importance of adding vector control, ITNs in this case, to MDA. Notwithstanding this, by $2004 \mathrm{mf}$ incidence in both villages had declined to around 7 cases/1000 person years. Our findings seem to support results from other studies indicating benefit of vector control in filariasis control (Pedersen \& Mukoko 2002; Bockarie et al., 2002a; 2009;Bogh et al., 1998; Michael et al., 2004; Odermatt et al., 2008;). A study conducted in Kenya (Bogh et al., 1998) reported great reductions (>90\%) in indoor-resting An. gambiae s.l. and An. funestus with Permethrin-impregnated mosquito nets. They concluded that mosquito nets provided personal protection against $W$. bancrofti transmission by the two mosquito species as well as Culex quinquefasciatus. Another study conducted in Kwale district of Kenya (Pedersen \& Mukoko 2002), where the three vectors transmit W. bancrofti, reported great reductions $(>90 \%)$ in transmission. The importance of adding vector control to LF elimination programmes has been well summarized in a recent article (Bockarie et al., 2009) where the authors, using mathematical modelling, propose three major strategic roles of vector control. They urge that including vector control to LF elimination programmes would reduce number of years of required drug administration, lower drug coverage requirement, and sustain long-term parasite elimination from treated communities.

Lower prevalence of $W$. bancrofti $m f$, antigenaemia and hydrocoele in mosquito net users compared to non-users was reported in Papua New Guinea (Bockarie et al., 2002a). In our study, there was no difference in overall prevalence of elephantiasis between the villages or across the years. On the other hand, in our study, an initial decrease in hydrocoele prevalence was seen in 2000 and might be explained by DEC which was administered for a one year period. Our results for the initial period are thus similar to those seen in Papua New Guinea (Bockarie et al., 2002b); where annual treatments with single dose of diethylcarbamazine plus ivermectin or diethylcarbamazine alone had great impact on hydrocoeles. Furthermore, the higher prevalence of hydrocoeles in Mpapayu compared to Magoda could also be explained by the fact that more males underwent hydrocelectomy in Magoda which were performed before Mpapayu was included in the study. Notwithstanding this, a few males with chronic hydrocoeles in both villages had participated in another study looking into effect of DEC on reducing the size of hydrocoeles of filarial origin (Bernhard et al., 2001).

The limitation of our data is that from the baseline we were not able to tell whether there was a killing or reduction of $m f$ or worms following ageing or effect of treatment and this might have resulted in biased estimates of the incidence.

In conclusion, our results suggest that although one year low monthly DEC dose seemed effective, as evidenced by the findings from Mpapayu, in order for MDA to induce 
desired impact, it might be necessary to maintain long term MDA administration. Inclusion of ITNs, preferably at the onset of whole community intervention, might have added advantage. Longer intervention period where both MDA and ITNs strategies are employed simultaneously might provide sustained effect on LF. Widespread use of ITNs at the end of MDA and after cessation of MDA can prevent a rise in incidence. Furthermore, distribution of ITNs several years after cessation of MDA can suppress residual transmission. The current global LF elimination programme, also running in Tanzania since 2004 will now benefit from the mass distribution of ITNs.

\section{Competing interests}

The authors declare that they have no competing interests

\section{Authors' contributions}

MML participated in designing the study, analysis plan, interpretation of the results and manuscript preparation. BPM assisted with data collection coordinating, data management and analysis, interpretation of the results and manuscript preparation. MDS assisted with data collection coordinating, and manuscript preparation. SG assisted with data collection, and manuscript preparation. IBC assisted with designing the study, interpretation of the results and preparation of the manuscript. All authors read and approved the final manuscript.

\section{Acknowledgements}

All individuals who agreed to participate in the study and the village leadership are thanked for their cooperation. We are greatly indebted to the late Dr. Rwehumbiza Rwegoshora for assisting with the CFA testing using ICT cards. We would like to acknowledge excellent technical support by Julius Mhina, Juma Akida, Lincoln Malle, Zacharia Savaeli and Alban Machaga. We are also thankful to Rehema Hussein, Mwanaisha Said and N. Mziray for clinical support during field work. Our sincere gratitude goes to Magreth Hamisi, Hatibu Athumani, and Zahabu Kauzeni for providing support in the field and in the laboratory. This study was funded by DANIDA through ENRECA project.

\section{References}

Alifrangis, M., Lemnge, M.M., Ronn, A.M., Segeja, M.D., Magesa, S.M., Khalil, I.F. \& Bygbjerg, I.C. (2003) Increasing prevalence of wildtypes in the dihydrofolate reductase gene of Plasmodium falciparum in an area with high levels of sulfadoxine/pyrimethamine resistance after introduction of treated bed nets. American Journal of Tropical Medicine and Hygiene 69, 238-243.

Bernhard, P., Magnussen, P. \& Lemnge, M.M. (2001) A randomized, double-blind, placebocontrolled study with diethylcarbamazine for the treatment of hydrocoele in an area of Tanzania endemic for lymphatic filariasis. Transactions of the Royal Society of Tropical Medicine and Hygiene 95, 534-536. 
Bernhard, P., Makunde, R.W., Magnussen, P. \& Lemnge, M.M. (2000) Genital manifestations and reproductive health in female residents of a Wuchereria bancrofti-endemic area in Tanzania. Transactions of the Royal Society of Tropical Medicine and Hygiene, 94, 409-412.

Bockarie, M.J., Pedersen, E.M., White, G.B. \& Michael, E. (2009) Role of vector control in the global program to eliminate lymphatic filariasis. Annual Review of Entomology 54, 469487.

Bockarie, M.J., Tavul, L., Kastens, W., Michael, E. \& Kazura, J.W. (2002a) Impact of untreated bednets on prevalence of Wuchereria bancrofti transmitted by Anopheles farauti in Papua New Guinea. Medical and Veterinary Entomology 16, 116-119.

Bockarie, M.J., Tisch, D.J., Kastens, W., Alexander, N.D., Dimber, Z., Bockarie, F., Ibam, E., Alpers, M.P. \& Kazura, J.W. (2002b) Mass treatment to eliminate filariasis in Papua New Guinea. New England Journal of Medicine 347, 1841-1848.

Bogh, C., Pedersen, E.M., Mukoko, D.A. \& Ouma, J.H. (1998) Permethrin-impregnated bednet effects on resting and feeding behaviour of lymphatic filariasis vector mosquitoes in Kenya. Medical and Veterinary Entomology 12, 52-59.

Lusingu, J.P., Vestergaard, L.S., Mmbando, B.P., Drakeley, C.J., Jones, C., Akida, J., Savaeli, Z.X., Kitua, A.Y., Lemnge, M.M. \& Theander, T.G. (2004) Malaria morbidity and immunity among residents of villages with different Plasmodium falciparum transmission intensity in North-Eastern Tanzania. Malaria Journal 3, 26.

Mboera, L., Pedersen, E., Salum, F., Msuya, F. \& Sambu, E. (1997) Transmission of malaria and bancroftian filariasis in Magoda, northeast Tanzania. Malaria and Infectious Diseases in Africa 7, 61-67.

McMahon, J.E., Marshall, T.F., Vaughan, J.P. \& Abaru, D.E. (1979) Bancroftian filariasis: a comparison of microfilariae counting techniques using counting chamber, standard slide and membrane (nuclepore) filtration. Annals of Tropical Medicine and Parasitology 73, 457-464.

Meyrowitsch, D.W. \& Simonsen, P.E. (1998) Long-term effect of mass diethylcarbamazine chemotherapy on bancroftian filariasis, results at four years after start of treatment. Transactions of the Royal Society of Tropical Medicine and Hygiene 92, 98-103.

Meyrowitsch, D.W., Simonsen, P.E. \& Magesa, S.M. (2004) A 26-year follow-up of bancroftian filariasis in two communities in north-eastern Tanzania. Annals of Tropical Medicine and Parasitology 98, 155-169.

Meyrowitsch, D.W., Simonsen, P.E. \& Makunde, W.H. (1995a) A 16-year follow-up study on bancroftian filariasis in three communities of north-eastern Tanzania. Annals of Tropical Medicine and Parasitology 89, 665-675.

Meyrowitsch, D.W., Simonsen, PE. \& Makunde, W.H. (1995b) Bancroftian filariasis: analysis of infection and disease in five endemic communities of north-eastern Tanzania. Annals of Tropical Medicine and Parasitology 89, 653-663.

Meyrowitsch, DW., Simonsen, P.E., \& Makunde, W.H. (1996) Mass diethylcarbamazine chemotherapy for control of bancroftian filariasis through community participation: comparative efficacy of a low monthly dose and medicated salt. Transactions of the Royal Society of Tropical Medicine and Hygiene 90, 74-79.

Michael, E. \& Bundy, D.A. (1997) Global mapping of lymphatic filariasis. Parasitology Today $13,472-476$.

Michael, E., Malecela-Lazaro, M.N., Simonsen, P.E., Pedersen, E.M., Barker, G., Kumar, A., \& Kazura, J.W. (2004) Mathematical modelling and the control of lymphatic filariasis. Lancet Infectious Diseases 4, 223-234. 
Michael, E., Simonsen, P.E., Malecela, M., Jaoko, W.G., Pedersen, E.M., Mukoko, D., Rwegoshora, R.T. \& Meyrowitsch, D.W. (2001) Transmission intensity and the immunoepidemiology of bancroftian filariasis in East Africa. Parasite Immunology 23, 373-388.

Odermatt, P., Leang, R., Bin, B., Bunkea, T. \& Socheat, D. (2008) Prevention of lymphatic filariasis with insecticide-treated bednets in Cambodia. Annals of Tropical Medicine and Parasitology 102, 135-142.

Pedersen, E.M. \& Mukoko, D.A. (2002) Impact of insecticide-treated materials on filaria transmission by the various species of vector mosquito in Africa. Annals of Tropical Medicine and Parasitology 96 (Suppl 2), S91-S95.

Simonsen, P.E., Lemnge, M.M., Msangeni, H.A., Jakobsen, P.H. \& Bygbjerg, I.C. (1996) Bancroftian filariasis: the patterns of filarial-specific immunoglobulin G1 (IgG1), IgG4, and circulating antigens in an endemic community of northeastern Tanzania. American Journal of Tropical Medicine and Hygiene 55, 69-75.

Simonsen, P.E., Meyrowitsch, D.W., Jaoko, W.G., Malecela, M.N., Mukoko, D., Pedersen, E.M., Ouma, J.H., Rwegoshora, R.T., Masese, N., Magnussen, P., Estambale, B.B. \& Michael, E. (2002) Bancroftian filariasis infection, disease, and specific antibody response patterns in a high and a low endemicity community in East Africa. American Journal of Tropical Medicine and Hygiene 66, 550-559.

Simonsen, P.E., Niemann, L., \& Meyrowitsch, D.W. (1997) Wuchereria bancrofti in Tanzania: microfilarial periodicity and effect of blood sampling time on microfilarial intensities. Tropical Medicine E International Health 2, 153-158. 